\title{
An Experimental Teaching Platform Based on Multi-source Driven Mode
}

\author{
Ming $\mathrm{Si}^{1, \mathrm{a}}$, Zhanli $\mathrm{Li}^{1, \mathrm{~b}}$ \\ ${ }^{1}$ School of Computer Science and Technology, Xi'an University of Science and Technology, Xi'an, \\ 710054, China \\ aemail: xust_siming@163.com, bemail: lizl@xust.edu.cn
}

Keywords: Experimental Teaching; Excellent Engineers; Multi-source Driven Mode; Platform

\begin{abstract}
Experimental teaching is basic platform for training excellent engineers. It is also an important pillar for students to improve their practice and innovation capabilities. The paper analyzes the problems in experimental teaching. An effective way is proposed to solve these problems comprehensively. The way is that experimental teaching platform based on multi-source driven mode is built. The platform operation results show that the problem of enhancing experimental teachers' abilities is resolved. The cooperation between schools and enterprises is strengthened. The quality of experimental teaching is improved. The experimental teaching resource is shared. The platform can greatly improve students' practical and innovative ability.
\end{abstract}

\section{Introduction}

Xi'an University of Science And Technology Computer College existing computer science and technology, information and computer science, network engineering and software engineering, four undergraduate professional, computer application technology and software engineering two class a master's degree, more than 1400 students. Experimental teaching is the important support and platform for training practice and innovation ability of Excellence Engineer in universities. In recent years, many reform achievements have been obtained in various aspects. However, Experimental teaching has many problems which are not conducive to the cultivation of the quality of experimental teaching and improve students' practical and innovative abilities in training of teachers, use of teaching mode, teaching content design, teaching resources development, the management operation mechanism and other aspects.

1. The need to strengthen the construction of experimental teaching team

The concept of paying attention to theoretical teaching and ignoring the practice teaching makes teachers used in classroom teaching and does not adapt to the practice teaching including experimental teaching. Do not pay attention to the improvement of practical ability and experimental teaching. It leads to the lack of practice experience. Practical ability is not strong. At the same time, the recognition mechanism of the teaching work often ignores the recognition of teachers' experimental teaching level. It dampens the enthusiasm of teachers to undertake experimental teaching task. This situation affects the development of the students' practical and innovative ability.

2. The need to expand the extension of experimental teaching

The combined degree of school and enterprise is not high. Experimental teaching can not be timely tracking the latest technology and product information. Absorption of enterprise quality technology and human resources is not very good. Experimental teaching content and environment close to the enterprise demand for students and teachers can not be created. It leads to deviation of experimental teaching content and actual demand of enterprise and development trend of professional. It is not conducive to the cultivation of engineering talents the society needs. At the same time, the fusion degree of teaching and researching in experimental teaching is not deep. It is not conducive to the implementation of the undergraduate tutorial system [1]. The ways to enhance students' abilities of independent research and scientific research through the study in project research are missing. It is not conducive to the cultivation of students' team spirit. It is not conducive to the cultivation of students' innovation consciousness and ability. 
3. The need to deepen the reform of experimental teaching content and mode

The conversion of teaching and learning is neglected. It is not conducive to the cultivation of innovative thinking and innovative ability talents. The experimental teaching reform deepening and effect are greatly restricted.

The reform of experimental teaching modes and means is neglected. Teachers do not focus on the use of teaching patterns and means appropriate according to the characteristic of experimental teaching. They used to copy the theory of classroom teaching mode and teaching means. This situation has a great impact on students' interest and enthusiasm in the experiment.

The experimental teaching content update is neglected. The knowledge structure of experiment teaching is not reasonable. The requirements of enterprises and professional technology development can not be followed. It is not conducive to the realization of students' occupation career goals.

4. The need to improve experimental teaching resource informatization construction

The construction of experimental teaching information resources is not enough deep, especially on acquisition, processing, storage and release of experimental teaching information resources. The effective use of high quality resources of experimental teaching is greatly affected.

Under the condition of informatization, the study of experimental teaching mode is not enough. Especially on the combination of traditional experimental teaching mode and informatization experimental teaching mode, the effect of the use of information technology in the experimental teaching is reducing.

\section{The Scheme of Experimental Teaching Reform}

1. The construction of experimental teaching platform based on multi-source driven mode

Based on the current situation of local colleges and universities in west and experimental teaching reform of Xi'an University of Science and Technology, the experiment teaching of Computer College of Xi'an University of Science And Technology is put as the research and practice object. The paper analyzes the problems in experimental teaching. An effective way is proposed to solve these problems comprehensively. The way is that experimental teaching platform based on multi-source driven mode is built. It is showed in figure 1. Experimental teachers' team building is traction force. Experimental teaching in extension form is boost force. Double-melt experimental teaching structure is internal force. And experimental teaching network platform is braced force.

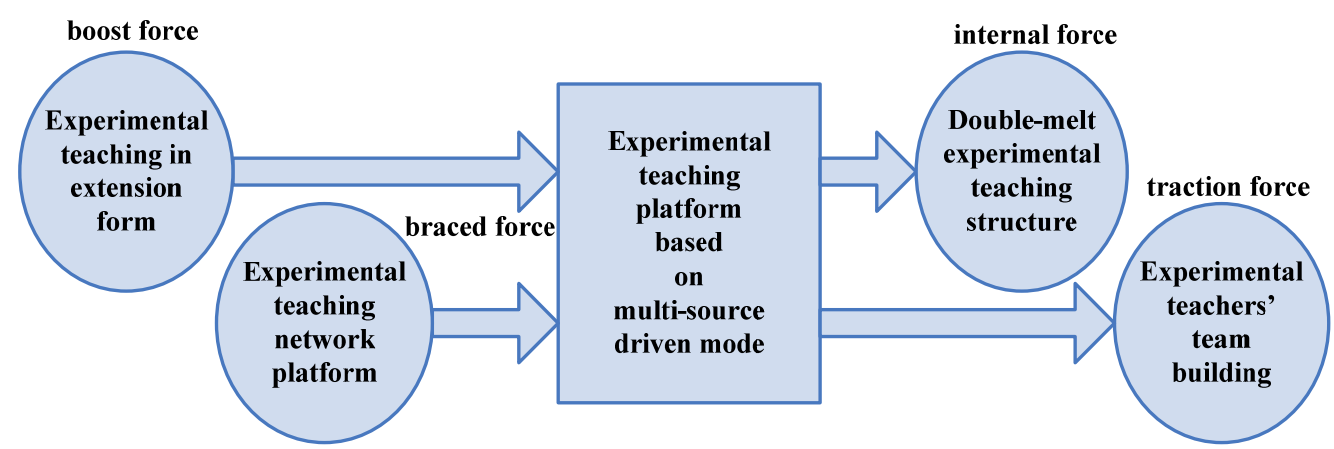

Figure 1. Experimental teaching platform based on multi-source driven mode

2. The experimental teaching reform measures

(1) The information collection and analysis modeling

On the basis of deep investigation, the functions of teaching information collection system established in teaching reform is expanded. Information acquisition of experiment teaching and teachers is designed and carried out. Many factors affecting teachers' investment enthusiasm of experimental teaching and improving teachers' practical abilities are determined. The collection of reasonable influent factors and mutual connection are obtained. The scientific qualitative and quantitative model is established.

(2) The design of incentive policies and measures of the training 
According to the mutual connection of many factors affecting teachers' investment enthusiasm of experimental teaching and improving teachers' practical abilities, the qualitative and quantitative model are analyzed. Various corresponding incentive experimental teaching policies and improving teachers' practical ability cultivation measures are researched and designed. School-enterprise combined training, part-time and rotation, exchange and other regulations [2] are researched and established. The special training funds of experimental teaching reform, teachers experiment skill competition and other measures are adopted. According to the results of practice, the design and establishment of incentive policies and training mechanism are constantly improved.

(3) The construction of win-win school-enterprise cooperation mechanism

According to school-enterprise cooperation mechanism, enterprise technical experts are hired for teaching and training students. The enterprises are invited to joint laboratory for scientific research activities. The enterprise projects, development experience and technology products are integrated into the experimental teaching. Students' practical experience is increased through project training. Based on the existing practice base, practice base will be extended to more enterprises and research institutes. More opportunities for the students to go out of the campus and go into the enterprise will be made. Through the complementary advantages of enterprises and universities, not only the enterprise demand for talents is meet, but also the university personnel training goal is achieved. It can make up the shortage of experimental teaching funding, but also shortens the talent market adaptation period. The win-win plan will be realized.

(4) The construction of feasible integration system of teaching and researching

Corresponding encourage policies are formulated to support scientific and engineering research of school and enterprises into the laboratory. The transformation of research content and experimental teaching content, the transformation of scientific research products and experiment teaching instrument and the combination method of experiment teaching and scientific research activities are explored. The innovation of experimental teaching process is researched. The development process of research products are put into experiment teaching timely and phased. The research and teaching interactive base is established by college in order to encourage teachers to filter their scientific research projects. These contents are designed to be a series of experiment teaching contents. Scientific research achievements and development of new technologies are introduced into the experimental teaching constantly. The integration degree of theoretical teaching and experimental teaching is improved, so that students understand and grasp the ways and means of theoretical knowledge into practical abilities.

(5) The construction of grading and progressive experimental teaching content system

Primary level corresponds to experimental basic training platform [3], including computer-based experiments, the basic training of students in science and technology associations, software programming and lectures, in order to offer the training of students' basic skills.

Intermediate level corresponds to the integrated design experiment platform [4], including basic experiments, course design, graduation design, research training program of college students and science and technology competition at school level, in order to enhance students' professional engineering skills.

Advanced level corresponds to exploration innovative experimental platform [5], including national and international science and technology competitions, independent research and innovative projects and research projects, in order to train and temper students' practical and innovative ability.

(6) The construction of a new type of experimental teaching structure

A variety of teaching mode is used by traditional experimental teaching. It is conducive to stimulate the initiative of teachers to help teachers to organize and guide the students. It is conducive to systematic acquisition of subject knowledge.

The interface operational information technology experimental teaching model is built. According to the teaching objectives, experimental learning environment and experimental learning resources are prepared for students, including simulation experiments, virtual experiments, and the control of experimental teaching resources library. According to the teaching objectives, 
experimental subjects are selected by students. Under the conditions of existing knowledge structure and the theory, conjecture and hypothesis are proposed by students. Experimental strategy is made. The correct methods of operation or some kind of law are summed up.

The project cooperative information technology experimental teaching model is built. The model is the product of the combination of information technology and traditional experiment. It is suitable for high-level teaching. Under the guidance of a teacher, the topics are selected by students. Through discussions, exchange and cooperation in the exploration, the knowledge is acquired and applied in the process of experimental exploration.

A two-melt experimental teaching structure is built. The grading and progressive experimental teaching content system is relied on. Denotative experiment teaching and experimental teaching resources information platform are supported. According to the different teaching content and teaching methods, knowledge and skills combined experimental teaching module is designed.

(7) The development of the Web-based experimental teaching network platform

The experimental teaching resource library is researched and developed. Experimental teaching quality teaching resources can be managed and used. Experimental teaching quality resources are shared. Experimental teaching time, space and content are all open. A free and independent lab environment is created for students.

\section{Conclusion}

Then the Computer Experiment Center will be relied on to consolidate what has been achieved. We will continue to deepen the experimental teaching reform and standardize laboratory management. We will start working in some aspects, such as network and information security laboratory construction, computer hardware laboratory construction and software engineering professional practice system construction. We will establish first-class laboratory environment and teaching staff, and work hard to achieve the goal of building of the provincial computer experimental teaching demonstration center.

\section{Acknowledgement}

My deepest gratitude goes first and foremost to Professor Long Xihua and Professor Li Zhanli, for their constant encouragement and guidance. Then my thanks would go to project team colleagues, they are Luo Xiaoxia and Jin Hongmei. Thank you for their invaluable works and help.

\section{References}

[1] Xianming Shi, Mei Zhao, Haidan Wang, and Bing Bing. Systematic analysis of undergraduate tutorial system in universities [J]. Journal of Heibei University of Science and Technology (Social Sciences), 2012: 12 (2): 96-101.

[2] Zhaojin $\mathrm{Wu}$. Thinking of the joint training mode of post graduates between school and enterprise [J]. Journal of Anhui University of technology (Social Sciences), 2012: 29 (1): 103-105.

[3] Qi Chen. Probe into reform of computer professional experimental teaching [J]. Research in Teaching, 2005: 28 (6): 547-548.

[4] Zhaohui Huang, Yangai Liu, Minghao Fang, Jinhong Li, Gaoxiang Du. Teaching optimization for enhancing the technological innovation ability of college students in materials major [J]. Chinese Geological Education, 2009: 69 (1): 124-126.

[5] Xiaojian Wang, Zhenhua Wang, Yusen Li. Emipirical discussion on interactive pattern of industry, academic and research [J]. Journal of Chang'an University (Social Science Edition), 2009: 11(3): 44-48. 